\title{
Perceived stress among university students in Oman during COVID-19-induced e- learning
}

\author{
Mustafa Malik ${ }^{1 *}$ and Sarfaraz Javed ${ }^{2}$
}

\begin{abstract}
Background: Higher education institutions across the world moved to e-learning in response to the disruptions caused by the pandemic. While e-learning has an advantage for students that they can attend to their courses from anywhere at their convenience, yet the sudden disruptive shift to e-learning during the pandemic saw students facing many challenges, which had strong ability to induce mental health issues among the students. This study aimed at examining the impact of COVID-19-induced e-learning on the university students' stress perceptions in Oman.

Results: A total of 966 usable responses were received. The results showed that $96.9 \%$ (moderate stress $=82.5 \%$ and high stress $=14.4 \%$ ) reported having experienced stress through e-learning during COVID-19. The results further indicated that there was a significant negative correlation between perceived stress and the students' academic performance. The family support and institutional support were observed to have a significant effect on students' stress perception.

Conclusions: Students are away from the physical campuses over a year now, continuing their courses and programs online. The numerous challenges they are facing through e-learning, together with the prevailing uncertainty, have intensified stress among them. The continued stress over time will not only affect their academic performance, but their mental and physical health as well, as the stress has proven to be one of the major causes of various physical and mental disorders. While e-learning seems to emerge as a new normal, the students require proper attention, help, and support from their families and institutions. The institutions should revisit their online courses and program delivery mechanisms, methods, and practices to ensure that students are not over stressed.
\end{abstract}

Keywords: Stress, Students, Higher education, COVID-19, Oman

\section{Background}

The spread of novel coronavirus (COVID-19) disrupted all economic and social activities around the world. Higher education has been one of the worst hit sectors. Being intensively interactive in nature, this sector saw a comparatively early and complete shutdown across the globe. In Oman, the government announced the closure of all educational institutions by mid of March 2020 . Responding to the pandemic and the subsequent

\footnotetext{
*Correspondence: mustafamalik@unizwa.edu.om

${ }^{1}$ Department of Management, University of Nizwa, Nizwa, Oman

Full list of author information is available at the end of the article
}

advisories by regulating bodies to suspend on-campus academic activities, higher education institutions (HEIs) switched to online mode to deliver academic programs. Like elsewhere, most of the HEIs in Oman had no prior experience of delivering programs completely online and therefore, applied varied approaches depending on their size, governance models, and disciplinary differences [1]. Over more than a year in pandemic now, HEIs in Oman are continuing their programs online. With many improvements and innovations in online teaching and learning process over the past 1 year, students have started adapting to this new normal. 
However, weakness of online teaching infrastructure, inexperience of teachers regarding new technologies, information gap, and complex home environment still exist [2]. Students, through COVID-19-induced online education are facing numerous challenges, such as instructional [3] technological, and technical [3-5]; social and family atmosphere [5]; home confinement [6, 7]; emotional and psychological $[3,8]$. Furthermore, many students do not find a suitable space in their homes for effective learning and do not have access to sufficient hardware or internet which constrains their home learning [9].

Though online education for HEIs is not anything new, as many HEIs have been offering full courses and/ or full programs online, yet students enrolled in full online instruction-based programs, who were not familiar with such experiences faced a system shock [10].

All these challenges faced by the students in online education during COVID-19 have a strong ability to induce mental health issues among the students. One commonly experienced mental health issue by university students is the academic stress, which is mostly due to the students' apprehension of loss of grades and fear of failure [11]. Fear of lower performance and delay in completion of studies are also the reasons to induce stress among students during COVID-19. Many studies conducted during last 1 year focusing on university students' mental health during COVID-19, such as [12-16] concluded that COVID-19 had a negative impact on the mental health and wellbeing of the university students. Besides earlier studies such as [17-19] have also shown that uncertainties due to public health emergencies, such as H1N1 influenza, Ebola, SARS, and MERS, caused negative psychological effects on university and college students. Furthermore, the negative psychological impacts are aggravated if the public emergencies accompany with home confinement [6,7], which is what happened across the globe, during COVID-19.

In the context of Oman, there are very few studies conducted regarding the impact of COVID-19 on the mental health of people and these are mostly related to the youth in general [20], general population [21], and health workers [21]. Regarding the mental health of university students during COVID-19 in the context of Oman, we did not find any study except for one by Alqassabi et al. [22], published in Arabic language. The available literature indicates that there is little being published on impact of COVID-19-induced e-learning on the stress perceptions of university students in Oman. While there is considerable literature on this subject available in the Western and Eastern contexts, these cannot necessarily be generalized to Arab world considering that its culture, social structure, and social norms vary greatly from the Western and Eastern cultures.
Thus, the present study aimed at examining the impact of COVID-19-induced e-learning on the university students' stress perceptions in Oman, thereby filling the gap in the literature that exists in the Oman context on the topic under study. The results of this study provide insights to the higher education educators, administrators, and policy makers to enhance e-learning implementation in a way that ensures mental and psychological wellbeing of the students.

\section{Methods \\ Sample}

This study was undertaken at the University of Nizwa, Oman. It is the second largest and the only non-profit private university in the country. The university comprises of four colleges namely College of Arts and Sciences (CAS), College Economics, Management and Information Systems (CEMIS), College of Pharmacy and Nursing (CPN), and the College of Engineering and Architecture (CEA). A total of 5269 students were registered across all undergraduate programs in the university for Fall 2020 [CAS $=2556$ (48.5\%); CEMIS $=1569$ $(29.8 \%) ; \mathrm{CPN}=552(10.5 \%)$; and $\mathrm{CEA}=592(11.2 \%)]$ (data received from Center for Information Systems of the University by email on the request of the corresponding author). A self-administered questionnaire was sent online to all the registered students. A total of 966 [CAS $=573$ (53.5\%); CEMIS = 273 (28.3\%); CPN = 74 (7.7\%); and $\mathrm{CEA}=102(10.6 \%)]$ completed responses were received. The figures show that the percentage of respondents from each college is fairly proportionate to the percentage of total students in each college, thus the sample is fairly representative of each college of the university under study.

\section{Measures}

Perceived Stress Scale (PSS-10)

To assess the stress as perceived by the students, the Cohen's Perceived Stress Scale (PSS-10 [23];) was used. It is a self-reported questionnaire that measures the degree to which an individual appraises situation in his or her life as stressful. The scale consists of 10 items including 6 positively phrased and 4 negatively phrased items. Each item is rated by respondents on a 5-point scale ranging from 'never (0)' to 'very often (4)'. The scores for negatively phrased items are reversed and then the scores for all 10 items are added for each individual. The individual scores on PSS can range from 0 to 40 with higher scores indicating higher perceived stress ('low stress $=0-13$ ', 'moderate stress $=14-26$ ', and 'high stress $\left.=27-40^{\prime}\right)$. The scale has been used in numerous studies and has shown good reliability. Lee [24] in his review paper on the use of PSS-10 reported that Cronbach's alpha was evaluated at $>0.70$ in all 12 studies his 
research referred to. For the present study the Cronbach's alpha for PSS-10 scale was 0.76 .

\section{Stressors}

Potential factors leading to stress among the university students were derived from the literature [25-28] and after informal discussion with the students. The students' inputs were very beneficial as it helped the authors to identify factors that were more relevant to online education and in the present pandemic situation. A total of 14 potential source of stress were identified. These were grouped into three categories as academic stressors (7 items), psychological stressors ( 4 items), and social stressors (3 items). For each potential stressor, the respondents were asked to show their agreement or disagreement on a 5-point Likert scale ranged between 'highly agree as 5' and 'highly disagree as 1'. The 14 stressors used in this study showed an overall Cronbach's alpha of 0.78 .

\section{Procedures}

The survey for the present research was conducted online using Google forms, with the undergraduate students registered for Fall Semester 2020 at the University of Nizwa in Oman. A bilingual (Arabic and English) questionnaire was sent to the students through their university email and was also posted on the University's Moodle home page with the help of Center for Information Systems of the University to ensure wider participation. The survey was open between 6 December 2020 and 31 December 2020 which corresponded to week 13 to week 16 of the academic semester (last 4 weeks before the final examination). During this period, three email reminders were sent to all the students for completing the survey. In the introductory part of the questionnaire, the purpose of this research was briefly explained. Students were informed that the participation in the survey was completely voluntary and were asked to express their consent before proceeding to respond to the questionnaire. To conduct this study, we received an ethical approval from the Human Ethics Committee in the Office of the Vice Chancellor for Graduate Studies, Research and International Relations, University of Nizwa through its letter (EC Ref. No.: HREC-12-2020) on 17 November 2020.

\section{Statistical analysis}

The statistical analysis was performed using the Statistical Package for Social Science (SPSS-20). Apart from descriptive statistics, means, standard deviations, and Pearson correlation was used to analyze and interpret the data and write the results.

\section{Results}

\section{Descriptive statistics}

As presented in Table 1, a total of 966 studentparticipants responded to the survey. By gender, the respondents comprised of $84.4 \%$ females $(n=815)$ and $15.6 \%$ males $(n=151)$. The female:male ratio of respondents was proportionate to the female:male ratio of the total student population $(n=5269)$ registered for Fall 2020 in the university (females $=4603,87.3 \%$ ) and males $=666,12.6 \%$ ).

\section{Perceived stress among respondents}

As presented in Table 2, the results of this study showed that the mental health of students is negatively affected during the pandemic. Of 966 students surveyed, 936 (96.9\%) reported having experienced stress (moderate stress $=82.5 \%$ and high stress $=14.4 \%$ ). There were only

Table 1 Demographic characteristics of the respondents and mean score on PSS-10 $(n=966)$

\begin{tabular}{|c|c|c|c|c|c|}
\hline & & & & PSS10 & \\
\hline & & Number & $\%$ & Mean & SD \\
\hline \multirow[t]{2}{*}{ Gender } & Male & 151 & 15.6 & 21.0 & 4.3 \\
\hline & Female & 815 & 84.4 & 22.2 & 4.2 \\
\hline \multirow[t]{3}{*}{ Age } & $\leq 20$ & 424 & 43.9 & 21.9 & 4.3 \\
\hline & $21-25$ & 420 & 43.5 & 22.2 & 4.1 \\
\hline & $\geq 25$ & 122 & 12.6 & 21.3 & 4.3 \\
\hline \multirow[t]{2}{*}{ Marital status } & Married & 133 & 13.8 & 22.6 & 4.2 \\
\hline & Unmarried & 833 & 86.2 & 21.3 & 4.3 \\
\hline \multirow[t]{2}{*}{ Place of residence } & Rural & 578 & 59.8 & 21.9 & 4.6 \\
\hline & Urban & 388 & 40.2 & 22.1 & 4.7 \\
\hline \multirow[t]{2}{*}{ Family type } & Nuclear family & 480 & 49.7 & 21.5 & 4.4 \\
\hline & Joint family & 486 & 50.3 & 22.4 & 4.1 \\
\hline \multirow[t]{2}{*}{ Degree level } & Bachelor & 689 & 71.3 & 22.2 & 4.3 \\
\hline & Diploma & 277 & 28.7 & 21.3 & 4.1 \\
\hline \multirow[t]{4}{*}{ Study year } & Year 1 & 292 & 30.2 & 21.4 & 4.3 \\
\hline & Year 2 & 160 & 16.6 & 22.3 & 4.3 \\
\hline & Year 3 & 184 & 19.0 & 21.7 & 4.3 \\
\hline & Year 4 and above & 330 & 34.2 & 22.5 & 4.2 \\
\hline \multirow[t]{5}{*}{ CGPA } & $\leq 2.0$ & 99 & 10.2 & 21.6 & 3.6 \\
\hline & $2.00-2.49$ & 179 & 18.2 & 21.4 & 4.0 \\
\hline & $2.50-2.99$ & 248 & 25.7 & 22.0 & 4.0 \\
\hline & $3.00-3.49$ & 262 & 27.1 & 22.6 & 4.4 \\
\hline & $3.50-4.00$ & 178 & 18.4 & 21.6 & 4.8 \\
\hline \multirow[t]{4}{*}{ College } & CEMIS & 273 & 28.3 & 21.9 & 3.6 \\
\hline & CAS & 517 & 53.5 & 21.9 & 4.5 \\
\hline & CPN & 74 & 7.7 & 21.9 & 3.6 \\
\hline & CEA & 102 & 10.6 & 22.5 & 4.5 \\
\hline
\end{tabular}


Table 2 Stress among students on PSS 10 scale

\begin{tabular}{lll}
\hline Stress level & Number $(\boldsymbol{N}=\mathbf{9 6 6})$ & (\%) \\
\hline Low (PSS Score 0-13) & 30 & $3.1 \%$ \\
Moderate (PSS Score 14-26) & 797 & $82.5 \%$ \\
High (PSS Score 27-40) & 139 & $14.4 \%$ \\
\hline
\end{tabular}

$30(3.1 \%)$ students who reported having experienced low stress.

When comparing mean stress scores between groups, the stress score varied between 21.0 and 22.6 among all categories of respondents, thereby showing that on an average all the respondents experienced a high-moderate stress. Similarly, female students $(M=22.2, \mathrm{SD}=4.2)$ showed higher symptoms of stress compared to male students $(M=21.0, \mathrm{SD}=4.3)$, and the mean stress score observed for married students $(M=22.6, \mathrm{SD}=4.3)$ was higher as compared to unmarried students $(M=21.3$, SD = 4.2). Similarly, students from urban areas were comparatively more stressed than those living in rural areas, students living in joint families were comparatively more stressed than those living in nuclear families, students enrolled in bachelor's degree programs were comparatively more stressed than their counterparts in diploma degree programs. While comparing mean stress score of students based on the year of study, the students studying in Year 2 and Year 4 showed comparatively higher stress than those studying in Year 1 and Year 3. Based on the CGPA of the students, the students falling at the middle of the CGPA continuum (2.503.50) showed comparatively higher stress than those with lower $(\leq 2.0-2.5)$ and higher (3.5-4.0) CGPA. When comparing the students' mean stress scores based on the college they belonged to, the engineering students showed a comparatively higher stress (CEA, $M=22.5$, $\mathrm{SD}=4.5)$ than students of other three colleges (CEMIS, $M=21.9, \mathrm{SD}=3.6$; $\mathrm{CAS}, M=2.19, \mathrm{SD}=4.5$ and $\mathrm{CPN}$, $M=21.9, \mathrm{SD}=3.6$ ).

\section{Perceived institutional and family support}

Organizational (institutional) support [29] and social (including family) support [30] is generally perceived to have positive influence on peoples' health and wellbeing. In academic settings, the institutional support may refer to the academic and non-academic support and services provided by the institutions to its students. In the context of e-learning during COVID-19, it may refer to the online academic support available to the students from their mentors, advisors, and teachers as well as from the institution's academic support services such as online learning support, technical and technological support, communication with students, and response to students' academic concerns. On the other hand, family support during COVID-19 may refer to the support provided by a student's family in terms of time and space and family responsibilities etc. The respondents (students) were asked to evaluate the institutional and family support during COVID-19-induced e-learning as poor, moderate, or good. The results of this study, as presented in Table 3, showed that $95.2 \%$ (good $=66.9 \%$ and moderate $=28.3 \%$ ) students perceived family support as favorable compared to $72.5 \%$ (good $=21.7$ and moderate $=50.8 \%)$ perceiving institutional support as favorable. A considerable percentage of students (27.4\%) perceived the institutional support as poor.

\section{Self-reported academic performance}

One of the major factors leading to stress among the students and widely reported in the literature is the fear of losing grades and poor academic performance. In this study, the students when asked to compare their academic performance with that of pre-COVID-19 period, $39 \%$ reported poor academic performance compared to $27.6 \%$ reporting their academic performance has improved, and the rest $33.4 \%$ said that they have not observed any change in academic performance (Table 3 ).

\section{Stress factors}

Various factors contributed to the stress experienced by students in online education during the pandemic. These factors were categorized as (a) academic factors, (b) psychological factors, and (c) social factors. Table 4 presents ranking of perceived stress factors based on their mean. Among the academic factors, while all factors have been perceived as contributing to the students' stress with the mean varying between 3.63 (lowest) and 4.12 (highest), increased number of exams during online distance learning was perceived as the strongest factor leading to stress among students (mean $=4.12, \mathrm{SD}=0.98$ ) and sufficiency of learning materials provided by instructors was ranked at lowest (mean $=3.89, \mathrm{SD}=1.01)$. Among the psychological factors, again all the factors were perceived as contributing to the stress among the students with the mean score varying between 4.33 (highest) and 3.50 (lowest). Constant fear of losing grades (mean $=4.33, \mathrm{SD}$ $=0.93$ ), and worry about performance (mean $=4.27, \mathrm{SD}$ $=0.96$ ) were ranked as top two psychological stress factors. Among the social factors, concern for family sufferings, my family is suffering due to my over engagement in academic work (mean $=3.91, \mathrm{SD}=1.06)$ was ranked at highest.

\section{Correlation among variables}

This study showed that the academic performance was negatively correlated with the overall perceived stress $(r$ $=-.349, p<0.01)$, negatively correlated with perceived academic stressors $(r=-.511, p<0.01)$, negatively correlated with perceived psychological stressors $(r=-$ 
Table 3 Students perceived family support, institutional support and academic performance $(N=966)$

\begin{tabular}{|c|c|c|c|c|c|}
\hline & Poor & Moderate & Good & Mean & SD \\
\hline Perceived family Support & $47(4.9 \%)$ & $273(28.3 \%)$ & $646(66.9 \%)$ & 2.62 & .577 \\
\hline \multirow[t]{2}{*}{ Perceive institutional support } & $265(27.4 \%)$ & $491(50.8 \%)$ & $210(21.7 \%)$ & 1.94 & .699 \\
\hline & Poor & Same & Better & Mean & SD \\
\hline Perceived academic performance compared to pre-COVID19 & $377(39 \%)$ & $323(33.4 \%)$ & $266(27.6 \%)$ & 1.89 & .808 \\
\hline
\end{tabular}

.383, $p<0.01$ ), and also negative correlated with perceived social stressors $(r=-.100, p<0.01)$ (Table 5). Furthermore, when comparing the correlation of academic performance with the perceived stressors, it was observed that perceived academic stressors had a significantly higher negative correlation with academic performance $(r=-.511, p<0.01)$ compared to perceived psychological stressors $(r=-.383, p<0.01)$ and perceived social stressors $(r=-.100, p<0.01)$.

\section{Discussion}

The results of this study showed that COVID-19induced online learning had a negative impact on the mental health of university students in terms of perceived stress, which was reported as moderate to high by 96.9\% of the respondents. These results are consistent with most of the studies conducted during last 1 year such as 12], [13-16]. Higher stress among university students has been, most often, related to lower academic performance [31-33]. Through this study, it was observed that the students' perceived academic performance had a negative relationship with their overall perceived stress on PSS10 $(r=-.349, p<0.01)$.

Furthermore, the results showed that perceived family support has a negative relationship with perceived stress $(r=-.203, p<0.01)$ and positive relationship with the academic performance $(r=.262, p<0.01)$. Deihl et al. [34] observed that people who perceived lower support from family and friends were emotionally less positive and hence more stressed. Moreover, Solberg [35] opined that social support moderates the relationship between stress and distress, which means that people who perceive higher social (family) support report lower distress. It is important to mention here that Cohen et al. [[30], p. 4] defined social support as 'a process through which the social relationships promote health and wellbeing'.

While many studies have studied impact of social support on students' stress, the impact of institutional support on students' perceived stress has received little focus, especially in the studies those have been

Table 4 Ranking of stress factors by mean $(N=966)$

\begin{tabular}{|c|c|c|}
\hline Academic factors & Mean & SD \\
\hline 1. I have to attend to more exams than I used to attend before COVID-19 & 4.12 & 0.98 \\
\hline 2. Online education during COVID-19 has increased my academic workload & 3.96 & 1.03 \\
\hline 3. I am facing technical difficulties (no or poor access to required technology) & 3.96 & 1.08 \\
\hline 4. Online education has made it difficult to manage my time & 3.89 & 1.09 \\
\hline 5. I am facing difficulty understanding course contents through online educational platforms & 3.88 & 0.99 \\
\hline 6. My performance in exams has decreased during COVID-19 & 3.83 & 1.09 \\
\hline 7. Learning materials provided by the instructors are not sufficient. & 3.63 & 1.01 \\
\hline Overall academic & 3.89 & 0.75 \\
\hline \multicolumn{3}{|l|}{ Psychological factors $(N=966)$} \\
\hline 1. I have constant fear of losing grades & 4.33 & 0.93 \\
\hline 2. I am most of the time worried about my performance & 4.27 & 0.96 \\
\hline 3. I worry about my health & 4.13 & 1.05 \\
\hline 4. I am not able to concentrate during online lectures & 3.50 & 1.09 \\
\hline Overall psychological & 4.06 & 0.69 \\
\hline \multicolumn{3}{|l|}{ Social factors $(N=966)$} \\
\hline 5. My family is suffering due to my over engagement in academic work & 3.91 & 1.06 \\
\hline 6. I get very little support from my family to manage my academic requirements & 3.74 & 1.17 \\
\hline 7. My teachers are less cooperative in solving my academic problems & 3.50 & 1.06 \\
\hline Overall social & 3.72 & 0.82 \\
\hline
\end{tabular}


Table 5 Correlation among family support, social support, perceived stress, and academic performance

\begin{tabular}{|c|c|c|c|c|c|c|c|c|}
\hline & & 1 & 2 & 3 & 4 & 5 & 6 & 7 \\
\hline \multirow[t]{2}{*}{ 1. AcPer } & $r$ & 1 & $.262^{* *}$ & $.351^{* *}$ & $-.349^{* *}$ & $-.511^{* *}$ & $-.383^{* *}$ & $-.100^{* *}$ \\
\hline & Sig. & & .000 & .000 & .000 & .000 & .000 & .002 \\
\hline \multirow[t]{2}{*}{ 2. FamSup } & $r$ & $.262^{* *}$ & 1 & $.331^{* *}$ & $-.203^{* *}$ & $-.277^{* *}$ & $-.209^{* *}$ & $-.064^{*}$ \\
\hline & Sig. & .000 & & .000 & .000 & .000 & .000 & .047 \\
\hline \multirow[t]{2}{*}{ 3. InsSup } & $r$ & $.351^{* *}$ & $.331^{* *}$ & 1 & $-.296^{* *}$ & $-.401^{* *}$ & $-.343^{* *}$ & -.028 \\
\hline & Sig. & .000 & .000 & & .000 & .000 & .000 & .388 \\
\hline \multirow[t]{2}{*}{ 4. PerStress } & $r$ & $-.349^{* *}$ & $-.203^{* *}$ & $-.296^{* *}$ & 1 & $.415^{* *}$ & $.409^{* *}$ & $.126^{* *}$ \\
\hline & Sig. & .000 & .000 & .000 & & .000 & .000 & .000 \\
\hline \multirow[t]{2}{*}{ 5. AcaStress } & $r$ & $-.511^{* *}$ & $-.277^{* *}$ & $-.401^{* *}$ & $.415^{* *}$ & 1 & $.691^{* *}$ & $.389^{* *}$ \\
\hline & Sig. & .000 & .000 & .000 & .000 & & .000 & .000 \\
\hline \multirow[t]{2}{*}{ 6. PsyStress } & $r$ & $-.383^{* *}$ & $-.209^{* *}$ & $-.343^{* *}$ & $.409^{* *}$ & $.691^{* *}$ & 1 & $.452^{* *}$ \\
\hline & Sig. & .000 & .000 & .000 & .000 & .000 & & .000 \\
\hline \multirow[t]{2}{*}{ 7. SocStress } & $r$ & $-.100^{* *}$ & $-.064^{*}$ & -.028 & $.126^{* *}$ & $.389^{* *}$ & $.452^{* *}$ & 1 \\
\hline & Sig. & .002 & .047 & .388 & .000 & .000 & .000 & \\
\hline
\end{tabular}

${ }^{* *} p=<0.01$ (2-tailed)

${ }^{*} p=<0.05$ level (2-tailed)

$r=$ Pearson correlation coefficient, Sig. level of significance, AcPer academic performance, FamSup family support, InsSup institutional support, PerStress perceived stress (on PSS10 Scale), AcaStress academic stressors, PsyStress psychological stressors, SocStress social stresssors

conducted during the pandemic. Since during the pandemic there was an abrupt shift from the physical classroom to online platforms, the institutional support to the students, in terms of advising systems, instructions, program progress tracking, career planning, and technology support, had a considerable impact on how comfortable or not they were with the online learning. This study showed that the students' perception of institutional support has significant negative relation with students' perception of stress $(r=-.296, p<0.01)$. This demonstrates that higher education institutions' student support systems have a potential to mediate the stress, especially the academic stress, which in this study is significantly negatively correlated to perceived institutional support $(r=-.401, p<0.01)$ and academic performance $(r=-.511, p<0.01)$. Pascoe et al. [36] argue that enhancing student support in the education setting may improve the mental health of young people.

When comparing mean stress scores between groups, the stress score varied between 21.0 and 22.6 among all categories of respondents, thereby showing that on an average all the respondents experienced a high-moderate stress. These results are similar to other studies conducted during the pandemic such as [3,5-9].

When comparing the mean stress scores (see Table 1), female students $(M=22.2, \mathrm{SD}=4.2)$ showed higher symptoms of stress compared to male students $(M=$ 21.0, $\mathrm{SD}=4.3)$. The mean stress score observed for married students $(M=22.6, \mathrm{SD}=4.3)$ was higher as compared to unmarried students $(M=21.3, \mathrm{SD}=4.2)$. Similarly, students from urban areas were comparatively more stressed than those living in rural areas, students living in joint families were comparatively more stressed than those living in nuclear families, and students enrolled in bachelor's degree programs were comparatively more stressed than their counterparts in diploma degree programs. While comparing mean stress score of students based on the year of study, the students studying in Year 2 and Year 4 showed comparatively higher stress than those studying in Year 1 and Year 3. Based on the CGPA of the students, the students falling of the middle of the CGPA continuum (2.50-3.50) showed comparatively higher stress than those with lower $(\leq 2.0-2.5)$ and higher (3.5-4.0) CGPA. When comparing the students' mean stress scores based on the college they belonged to, the engineering students showed a comparatively higher stress (CEA, $M=22.5, \mathrm{SD}=4.5$ ) than students of other three colleges (CEMIS, $M=21.9$, $\mathrm{SD}=3.6$; CAS, $M=2.19, \mathrm{SD}=4.5$ and $\mathrm{CPN}, M=21.9, \mathrm{SD}=3.6$ ).

\section{Conclusions}

The spread of COVID-19 affected every aspect of human life. Its impact has been unprecedented. The closure of universities for on-campus face-to-face teaching and learning forced higher education institution across the globe to deliver programs online. Initially thought to be a temporary arrangement to deal with the crises, online education is emerging as a new normal. In Oman, as of now, higher education institutions are closed for oncampus teaching and learning for over a year, and courses and programs are delivered either completely online or through blended learning mode. The recent 
resurge in COVID-19-infected cases in the country has once again triggered a sense of uncertainty on the opening of universities for on-campus activities. Sahu [14] and Tayefi [37] observed that consistent closure of universities for on-campus classes triggered a sense of uncertainty among the students about their academic and professional career and intensified among them persistent mental health challenges. Given this context, the present study was conducted to investigate the impact of the COVID-19-induced online learning on university students' psychological health in Oman. The study further investigated the relationship between the students' perceived level of stress and their perceived family support and institutional support, as well as their academic performance.

The study showed the during the online teaching and learning induced by the pandemic, students in general have experienced a moderate to higher stress. The students' mental health is significantly affected by the support they perceive from their family and the institution, as these were observed to be negatively correlated to the perceived stress by students. Although, academic, social and psychological stressors were observed to have negative impact on students' mental health (perceived stress), yet academic stressors were observed to have comparatively higher negative correlation with students' perceived stress as compared to psychological and social stressors, during COVID-19-induced online learning.

Various studies have shown that mental health of populations is significantly affected when faced with public health emergencies, and university students are no exception to this fact. The COVID-19 pandemic has been more catastrophic than any other public health emergency witnessed in the recent past. University students have been out of the physical campuses over a year now, and courses and programs are, more or less, completely delivered online, and there seems to be no end to it, at least not for the next six months to 1 year.

If the students are perceiving continued stress over time, it will not only affect their mental health but physical health as well, as the stress has proven to be one of the major causes of various physical and mental disorders such as hypertension, depression, diabetes, asthma, obesity, and cardiovascular diseases [38-41]. Hence, the students require proper attention, help, and support from their families and institutions [12]. The institutions should revisit their online courses and program delivery mechanisms, methods, and practices to ensure that students are not over stressed, particularly in terms of number of assessments, academic workload, and technical difficulties they face.

\section{Limitations}

This study focuses on stress perceived by university students in Oman during COVID-19-induced online learning.
Although the results of this study provide significant insights on the students' perceived stress during online learning, as not many studies are available on the subject in the context of Oman, yet the findings of this study cannot be generalized for the entire country as the study was conducted on the students in a specific university. Further studies could be conducted involving a wider crosssectional sample across higher education institutions in Oman to generalize the findings.

\section{Abbreviations \\ COVID-19: Coronavirus disease 2019; HEls: Higher education institutions; MERS: Middle East respiratory syndrome; PSS-10: Perceived stress scale-10; SARS: Severe acute respiratory syndrome; SPSS: Statistical package for social science}

\section{Acknowledgements}

The lead author acknowledges the support of the Center for Information Systems at his university (University of Nizwa) for disseminating the survey questionnaire for this study to students and providing the data related to the number of students registered in the University during Fall 2020.

\section{Authors' contributions}

MM conceived and designed this research. He designed the questionnaire, collected data, performed the data analysis, and wrote the manuscript. SJ contributed in literature review and the proofreading of the manuscript. All the authors have read and approved the manuscript.

\section{Funding}

This research did not receive any funding from any source.

\section{Availability of data and materials}

All the data and materials relevant to this study are available with the corresponding author and can be made available on a reasonable request.

\section{Declarations}

\section{Ethics approval and consent to participate}

This study received the ethical approval from the Human Ethics Committee in the Office of the Vice Chancellor for Graduate Studies, Research and International Relations, University of Nizwa through its letter (EC Ref. No.: HREC-12-2020) on 17 November 2020. The online survey questionnaire used for this study contained an introduction which explained the purpose and objectives of the study and asked the respondents to complete the survey voluntarily. Since the survey was conducted online, the respondents' consent was sought through a declaration made at the end of the introduction to the survey on the first page of the questionnaire. Respondents could proceed to the next page of the questionnaire only if they have accepted to participate in the survey.

\section{Consent for publication}

Not applicable.

\section{Competing interests}

The authors declare that they have no competing interests.

\section{Author details}

${ }^{1}$ Department of Management, University of Nizwa, Nizwa, Oman.

${ }^{2}$ Department of Commerce, Aligarh Muslim University, Aligarh, India.

Received: 21 May 2021 Accepted: 25 July 2021

Published online: 04 August 2021

References

1. International Association of Universities, IAU (2020) Regional/National Perspectives on the Impact of COVID-19 on Higher Education. https://www. iau-aiu.net/IMG/pdf/iau_covid-19_regional_perspectives_on_the_impact_ of_covid-19_on_he_july_2020_.pdf. Accessed 08 Feb 2021 
2. Ali W (2020) Online and remote learning in higher education institutes: a necessity in light of Covid-19 pandemic. High Educ 10(3):16-25

3. Martin, A. (2020) How to optimize online learning in the age of coronavirus (COVID-19): A 5-point guide for educators. https://www.researchgate.net/ publication/339944395_How_to_Optimize_Online_Learning_in_the_Age_ of_Coronavirus_COVID-19_A_5-Point_Guide_for_Educators/link/5e71637ca 6fdcc37caf31289/download. Accessed 8 Feb 2021

4. Almaiah MA, Al-Khasawneh A, Althunibat A (2020) Exploring the critical challenges and factors influencing the e-learning system usage during COVID-19 pandemic. Educ Inf Technol 25(6):5261-5280. https://doi.org/10.1 007/s10639-020-10219-y

5. Zhong, R. (2020) The coronavirus exposes education's digital divide. The New York Times https://www.nytimes.com/2020/03/17/technology/chinaschools-coronavirus.html. Accessed 17 Jan 2020

6. Wang C, Pan R, Wan X, Tan Y, Xu L, Mclntyre RS et al (2020a) A longitudinal study on the mental health of general population during the COVID-19 epidemic in China. Brain Behav Immunity 87:40-48. https://doi.org/10.1016/ j.bbi.2020.04.028

7. Wang C, Pan R, Wan X, Tan Y, Xu L, Ho CS (2020b) Immediate psychological responses and associated factors during the initial stage of the 2019 coronavirus disease (COVID-19) epidemic among the general population in China. Int J Environ Res Public Health 17:1729

8. Daniel SJ (2020) Education and the COVID-19 pandemic. Prospects 49(1-2): 91-96. https://doi.org/10.1007/s11125-020-09464-3

9. Z Zhang W, Wang Y, Yang L, Wang C (2020) Suspending classes without stopping learning: China's education emergency management policy in the Covid-19 outbreak. J Risk Financ Manage 13(3):55

10. Ngampornchai A, Adams J (2016) Students' acceptance and readiness for Elearning in Northeastern Thailand. Int J Educ Technol in Higher Education 13(1):1-13

11. Goff AM (2011) Stressors, academic performance, and learned resourcefulness in baccalaureate nursing students. Int J Nurs Educ Scholarsh 8(1):1-20. https://doi.org/10.2202/1548-923X.2114

12. Cao W, Fang Z, Hou G, Han M, Xu X, Dong J, Zheng J (2020) The psychologica impact of the COVID-19 epidemic on college students in China. Psychiatry Res 287:112934. https://doi.org/10.1016/j.psychres.2020.112934

13. Marelli S, Castelnuovo A, Somma A, Castronovo V, Mombelli S, Bottoni D, Ferini-Strambi L (2020) Impact of COVID-19 lockdown on sleep quality in university students and administration staff. J Neurol 268:1-8

14. Sahu P (2020) Closure of universities due to Coronavirus Disease 2019 (COVID-19): impact on education and mental health of students and academic staff. Cureus 12(4):1-6

15. Son C, Hegde S, Smith A, Wang X, Sasangohar F (2020) Effects of COVID-19 on college students' mental health in the United States: interview survey study. J Med Internet Res 22(9):e21279. https://doi.org/10.2196/21279

16. Zhai $Y$, Du X (2020) Mental health care for international Chinese students affected by the COVID-19 outbreak. Lancet Psychiatry 7(4):e22. https://doi. org/10.1016/S2215-0366(20)30089-4

17. Sprang G, Silman M (2013) Posttraumatic stress disorder in parents and youth after health related disasters. Disaster Med Public health Prep 7(1): 105-110. https://doi.org/10.1017/dmp.2013.22

18. Wu P, Fang Y, Guan Z, Fan B, Kong J, Yao Z, Liu X, Fuller CJ, Susser E, Lu J, Hoven CW (2009) The psychological impact of the SARS epidemic on hospital employees in China: exposure, risk perception, and altruistic acceptance of risk. Can J Psychiatry 54(5):302-311. https://doi.org/10.1177/ 070674370905400504

19. Bai Y, Lin CC, Lin CY, Chen JY, Chue CM, Chou P (2004) Survey of stress reactions among health care workers involved with the SARS outbreak. Psychiatry Serv. 55(9):1055-1057. https://doi.org/10.1176/appi.ps.55.9.1055

20. Al Omari O, Al Sabei S, Al Rawajfah O, Abu Sharour L, Aljohani K, Alomari K, Alhalaiqa F (2020) Prevalence and predictors of depression, anxiety, and stress among youth at the time of COVID-19: An online cross-sectional multicountry study. Depress Res Treat 2020:1-9. https://doi.org/10.1155/2020/8887727

21. Sinawi HA, Al Balushi N, Al-Mahrouqi T, Al Ghailani A, McCall RK, Sultan A, Al-Alawi M (2021) Predictors of psychological distress among the public in Oman amid coronavirus disease 2019 pandemic: a cross-sectional analytical study. Psychol Health Med 26(1):131-144. https://doi.org/10.1080/1354 8506.2020.1842473

22. Alqassabi K, Althehli R, Alkhawaja A (2021) The predictive capacity of Coronavirus impacts with psychological adjustment among university students in Oman. J Educ Psychol Res 18(68):312-336
23. Cohen S, Kamarck T, Mermelstein R (1983) Perceived Stress Scale. J Health Soc Behav 24(4):385-396. https://doi.org/10.2307/2136404

24. Lee EH (2012) Review of the psychometric evidence of the perceived stress scale. Asian Nurs Res 6(4):121-127. https://doi.org/10.1016/j.anr.2012.08.004

25. Sreeramareddy CT, Shankar PR, Binu VS, Mukhopadhyay C, Ray B, Menezes RG (2007) Psychological morbidity, sources of stress and coping strategies among undergraduate medical students of Nepal. BMC Med Educ 7(1):1-8

26. Hamaideh SH (2011) Stressors and reactions to stressors among university students. Int J Soc Psychiatry 57(1):69-80. https://doi.org/10.1177/0020764 009348442

27. El Ansari W, Khalil K, Stock C (2014) Symptoms and health complaints and their association with perceived stressors among students at nine Libyan universities. Int J Environ Res Public Health 11(12):12088-12107. https://doi. org/10.3390/ijerph111212088

28. Pluut H, Curşeu PL, llies R (2015) Social and study related stressors and resources among university entrants: Effects on well-being and academic performance. Learn Individ Differences 37:262-268. https://doi.org/10.1016/j. lindif.2014.11.018

29. Eisenberger R, Armeli S, Rexwinkel B, Lynch PD, Rhoades L (2001) Reciprocation of perceived organizational support. J Appl Psychol 86(1):4251. https://doi.org/10.1037/0021-9010.86.1.42

30. Cohen S, Gottlieb B, Underwood L (2000) Social relationships and health. In: Cohen S, Underwood L, Gottlieb B (eds) Measuring and intervening in socia support. Oxford University Press, New York. https://doi.org/10.1093/med: psych/9780195126709.003.0001

31. Alotaibi AD, Alosaimi FM, Alajlan AA, Abdulrahman KAB (2020) The relationship between sleep quality, stress, and academic performance among medical students. J Fam Community Med 27(1):23-28. https://doi. org/10.4103/jfcm.JFCM_132_19

32. Lin XJ, Zhang CY, Yang S, Hsu ML, Cheng H, Chen J, Yu H (2020) Stress and its association with academic performance among dental undergraduate students in Fujian, China: a cross-sectional online questionnaire survey. BMC Med Educ 20:1-9

33. Meyer S, Larson M (2018) Physical activity, stress, and academic performance in college: does exposure to stress reduction information make a difference? Coll Stud J 52(4):452-457

34. Deihl LM, Vicary JR, Deike RC (1997) Longitudinal trajectories of self-esteem from early to middle adolescence and related psychosocial variables among rural adolescents. J Res on Adolescents 7(4):393-411. https://doi.org/10.12 07/s15327795jra0704_3

35. Solberg VS (1997) Examination of self-efficacy, social support, and stress as predictors of psychological and physical distress among Hispanic college students. Hisp J Behav Sci 19(2):182-201. https://doi.org/10.1177/07399863 970192006

36. Pascoe MC, Hetrick SE, Parker AG (2020) The impact of stress on students in secondary school and higher education. Int J Adolesc Youth 25(1):104-112. https://doi.org/10.1080/02673843.2019.1596823

37. Tayefi B, Eftekhar M, Tayefi M, Darroudi S, Khalili N, Mottaghi A (2020) Prevalence and socio-demographic correlates of mental health problems among Iranian health sciences students. Acad Psychiatry 44(1):73-77. https://doi.org/10.1007/s40596-019-01121-y

38. McEwen BS (1998) Protective and damaging effects of stress mediators. N Engl J Med 338(3):171-179. https://doi.org/10.1056/NEJM199801153380307

39. Hwang A, Peng L, Wen Y, Tsai Y, Chang L, Chiou S, Chen L (2014) Predicting all-cause and cause specific mortality by static and dynamic measurements of allostatic load: a 10-year population-based cohort study in Taiwan. J Am Med Dir Assoc 15(7):490-496. https://doi.org/10.1016/j.jamda.2014.02.001

40. Stauder A, Cserháti Z, Thege BK (2018) Decreasing the negative effects of work-related stress in unchanged working environments. Eur J Ment Health 13(2):163-183. https://doi.org/10.5708/EJMH.13.2018.2.4

41. Li M, Shu Q, Huang H, Bo W, Wang L, Wu H (2020) Associations of occupational stress, workplace violence, and organizational support on chronic fatigue syndrome among nurses. J Adv Nurs 76(5):1151-1161. https://doi.org/10.1111/jan.14312

\section{Publisher's Note}

Springer Nature remains neutral with regard to jurisdictional claims in published maps and institutional affiliations. 